\title{
BMJ Open Predictors for future activity limitation in women with chronic low back pain consulting primary care: a 2-year prospective longitudinal cohort study
}

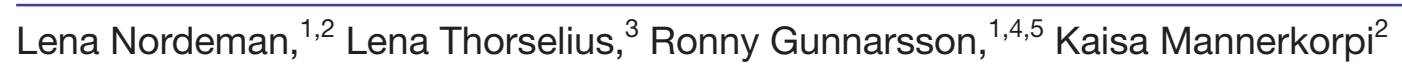

To cite: Nordeman L, Thorselius L, Gunnarsson R, et al. Predictors for future activity limitation in women with chronic low back pain consulting primary care: a 2-year prospective longitudinal cohort study. BMJ Open 2017;7:e013974. doi:10.1136/ bmjopen-2016-013974

- Prepublication history and additional material for this paper are available online. To view these files please visit the journal online (http://dx.doi. org/10.1136/bmjopen-2016013974).

Received 28 August 2016 Revised 8 April 2017 Accepted 10 April 2017
CrossMark

For numbered affiliations see end of article.

Correspondence to Dr. Lena Nordeman; Iena. nordeman@vgregion.se

\section{ABSTRACT}

Objectives To assess if body function, activity, participation, health-related quality of life and lifestyle behavioural factors can predict activity limitation in women with chronic low back pain (CLBP) in primary healthcare (PHC) 2 years later.

Design A 2-year prospective longitudinal cohort study within PHC.

Settings PHC in southwestern Sweden.

Participants The cohort comprised 130 women with CLBP attending PHC at baseline 2004-2005 and were reassessed after 2 years.

Measures The dependent outcome variable was selfreported activity limitation (Roland Morris disability questionnaire (RMDQ)) at 2-year follow-up. Independent predictors at baseline were age, body mass index, smoking, alcohol consumption, sleep quantity and quality, leisure time physical activity, a questionnaire of clinical manifestation of stress (Stress and Crises Inventory (SCl-93)), pain localisation, pain intensity, fatigue, anxiety, depression, RMDQ, work status, private social support, health-related quality of life and measures of physical performance specified as $6 \mathrm{~min}$ walk test (6MWT) and hand grip strength. Relation between baseline predictors and variation in later selfreported activity limitation (RMDQ) was analysed using multivariate linear regression.

Results Ninety-five per cent $(n=123 / 130)$ were followed up after 2 years. The participants were middle-aged (mean 45 (SD 10) years), mostly educated $>9$ years (88\%; 108/123), mainly living with another adult (76\%; 93/122) and born in Sweden (90\%; 111/123). Seventynine per cent $(97 / 123)$ were categorised as having work ability at baseline. The final prognostic model including 6MWT, SCl-93 and RMDQ at baseline explained $54 \%$ of the variance in self-reported activity limitation (RMDQ) at the 2-year follow-up.

Conclusions Lower physical performance, more severe clinical stress symptoms and more severe activity limitation predicted activity limitation after 2 years in women with CLBP within PHC. The results can give guidance for interventional trials aiming to improve physical capacity and decrease stress. The impact of the interaction between prognostic factors and interventions on activity limitation needs further investigation.

\section{Strengths and limitations of this study}

The main strength of this study is the longitudinal prospective design over 2 years within primary healthcare and high long-term follow-up (95\%).

- Measurements representing all the domains of International Classification of Functioning, Disability and Health complemented with lifestyle behavioural factors.

- The limitation of this study is the small sample size and that we included only women which limits the generalisability to men.

\section{INTRODUCTION}

Non-specific chronic low back pain (CLBP), defined as pain duration $>3$ months, is associated with variations of recurrent or persistent pain. ${ }^{2}$ CLBP has various impact on body functions, activity and participation in daily life $\mathrm{e}^{1-4}$ and it is a common cause for attending healthcare. ${ }^{1}$

Non-specific acute low back pain (LBP) is described to have a spontaneous course. ${ }^{125}$ However, after 1 year $63 \%-82 \%$ of primary care patients with LBP report to have recurrent LBP and 20\%-45\% impaired function. ${ }^{6-10}$ Prognostic factors for the transition from non-specific acute LBP to CLBP have previously been described in personal and socioeconomic areas as well as in all domains of the International Classification of Functioning, Disability and Health (ICF). ${ }^{6} 9$ 11-18 Women seems to have a greater risk for $\mathrm{CLBP}^{6}$ and when studying prognostic factors it is suggested to assess women separately. ${ }^{19-21}$ Previous prognostic models for the transition to CLBP explain $28 \%-51 \%$ of variability in the measured outcome. ${ }^{22}$ The outcomes, combination of included prognostic factors and statistical analyses often differ between studies, making comparisons or meta-analysis difficult. $^{18}$ 
Some studies have described similar prognostic factors for persistent CLBP as for the transition from non-specific acute LBP to CLBP. ${ }^{23}{ }^{24}$ Since the course of non-specific acute LBP and CLBP differs, more knowledge of prognostic factors for varying outcomes in patients with CLBP is warranted..$^{25} \mathrm{~A}$ previous review studying prognostic factors for delayed recovery in CLBP found no association between age, sex and the outcome measure of pain intensity and disability at short-term follow-up (eg, 6 weeks). Conflicting evidence was found for fear of avoidance as a predictor. ${ }^{26}$ At long-term follow-up (eg, 6 months), no association was found between smoking, pain intensity, fear of avoidance and the dependent variable disability. ${ }^{26}$ Conflicting evidence was found for age, sex and physical job demands and the outcome measure of pain intensity and disability. Moreover, conflicting evidence was found for the association between age, activities of daily living, pain intensity and physical job demand and the outcome return to work. ${ }^{26}$ However, recently a study showed that a physical performance test $(6 \mathrm{~min}$ walk test $(6 \mathrm{MWT}))$, depression and earlier work ability predicted later work ability in women with CLBP. ${ }^{27}$

The knowledge about various prognostic factors for the recovery in the long term for patients with CLBP is still insufficient. This study is an extended analysis of the material from the 2-year longitudinal cohort study of prognostic factors for work ability in women with CLBP. ${ }^{27}$ The present study aims to focus on the prognostic value of lifestyle behavioural factors, stress symptoms and physical performance for future activity limitation using the same material and measurements.

The aim was to assess if body function, activity, participation, health-related quality of life and lifestyle behavioural factors can predict the future variance of self-rated activity limitation in women with CLBP in primary healthcare (PHC) 2 years later.

\section{METHODS}

\section{Study design}

This 2-year prospective longitudinal cohort study included women $(n=130)$ with CLBP within PHC. ${ }^{28}$ Patients were assessed at baseline and were reassessed after 2 years. Predictors for later self-reported activity limitation (Roland Morris disability questionnaire (RMDQ)) were analysed by multivariate linear regression. Independent variables found to be associated with disability in patients with $\mathrm{CLBP}^{27}$ were complemented with lifestyle behavioural factors including body mass index (BMI), smoking, alcohol consumption, sleep quantity and quality, leisure time physical activity and a questionnaire of the clinical manifestation of stress. Other independent variables related to chronic pain were pain localisation, pain intensity, fatigue, anxiety, depression, work status, private social support health-related quality of life and two measures of physical performance.

Participants were assessed by a trained physical therapist in PHC both at baseline and after 2 years and included a structured interview, measure of body height and weight, and the two physical performance tests. Participants were asked to fill in a package of self-administrated questionnaires at the assessment and two at home. They were provided with a prepaid addressed envelope to return questionnaires. If no questionnaires were returned within 2 weeks, a reminder by telephone was made. Written informed consent was obtained from all patients.

\section{Selection of patients}

Female patients were identified by systematic search in medical charts for LBP diagnoses 'M545' (International Classification of Diseases, tenth revision) at eight PHC clinics in southwestern Sweden, a mixture of urban and rural populations, in 2004-2005. All patients who could be contacted, accepting participation and fulfilling the inclusion criteria were invited to enrol in the study. The inclusion criteria were female patient, LBP (pain between costal margins and gluteal folds) with or without referred leg pain. ${ }^{1}$ Further inclusion criteria were $>12$-week duration of symptoms, not pregnant, no known spinal pathology, no other severe comorbidity (eg, cancer, fracture, stroke, severe psychiatric disorders, mental retardation), age between 18 and 60 years, understanding and fluent in Swedish. At the 2-year follow-up, all patients included in the cross-sectional study $(n=130),{ }^{28}$ who could be contacted and accepting participation, were invited to the follow-up, containing the same study protocol as at baseline.

\section{Measurements}

The structured interview included questions about age, nationality, education level, family situation, work status, back pain history (onset, duration and symptoms), comorbidity and pharmacological treatment.

\section{Lifestyle behavioural factors}

Body mass index

Height and weight were assessed for calculating the BMI $\left(\mathrm{kg} / \mathrm{m}^{2}\right)$.

\section{Alcohol consumption}

For alcohol consumption, the Alcohol Use Disorders Identification Test (AUDIT-C) ${ }^{29}$ was used (range 0-12). Higher scores indicate higher alcohol consumption.

\section{Smoking}

Tobacco use was dichotomised into two categories, no smoker or smoker. The category no smoker required to never been smoking. The category smoker required to previously been a smoker or are reported to be currently smoking.

\section{Sleep}

For sleep quantity and quality, two questions was used. ' ${ }^{30}$ 'Do you think you get enough sleep?' (range 1-4) and 'On the whole, how do you think you sleep?" (range 1-4). Higher score indicates better sleep quantity and quality. 


\section{Stress symptoms}

To quantify clinical manifestations of stress symptoms, the Stress and Crises Inventory (SCI-93) was used (range $0-140$ ) where higher scores indicate more severe clinical stress symptoms. ${ }^{3132}$ A total score of $\leq 38$ indicates normal resources for activity and work. ${ }^{33}$

\section{Physical activity at leisure time}

The leisure time physical activity instrument (LTPAI) was used to assess the amount of physical activity in leisure time during a typical week. ${ }^{34}$ The number of hours spent for light, moderate and vigorous activities was registered and the total number of hours was used. ${ }^{34}$

\section{Body function}

\section{Physical performance tests}

The 6MWT was used to assess physical performance. ${ }^{35-37}$ The distance (metre) is measured while the patient walks up and down a $30 \mathrm{~m}$ corridor for $6 \mathrm{~min}$. The participant was instructed to walk as quickly as possible without running.

Hand grip strength was measured with an electronic instrument Grippit. ${ }^{38}{ }^{39}$ A sustained voluntary 10 s contraction was measured. The right-hand value was used for analyses in the present study.

\section{Number of pain localisation, pain intensity and fatigue}

For pain distribution, a drawing of the body was used to register pain localisations $(0-18) .{ }^{40}$ Pain intensity and fatigue during the last week was measured on a visual analogue scale (VAS) $0-100 \mathrm{~mm}$.

\section{Distress}

The Hospital Anxiety and Depression Scale (HADS), HADS-A, was used for assessment of anxiety (range 0-21) and the HADS-D for depression (range 0-21). Higher scores indicate greater anxiety or depression. ${ }^{41} 42$

\section{Activity limitations}

The RMDQ was used for self-reported activity limitation related to LBP. The RMDQ consists of 24 yes/no statements, where higher scores indicate greater activity limitation (range $0-24) .{ }^{43}$

\section{Participation}

Work status was dichotomised into two categories, work ability or not. The category work ability required work or study, full time or part time, applying for work, parental leave full-time or part-time or part-time disability pension. The category no work ability required full-time sick leave or full-time disability pension. Self-reported sick absenteeism has been shown reliable. ${ }^{44}$

\section{Environmental factors}

The four-item version of Medical Outcome Study Social Support Survey (MOS-SSS) registered private social support: emotional-informational, tangible, affectionate support and positive social interaction (range 1-5 for each item). Higher scores indicate more support (total range $4-20) .{ }^{45}$

\section{Health-related quality of life}

The short-form health survey (SF-36) was used for general health status. The physical component summary (PCS) score and the mental component summary (MCS) score representing an overall health index of physical or mental health (range 0-100) were used. ${ }^{46-48}$

\section{Statistical analysis}

Group characteristics are presented as mean and SD, median and 25th and 75th percentile or the number and percentage at baseline. Percentage change for RMDQ was constructed by subtracting baseline value from 2-year follow-up value. The change was divided with baseline and multiplied by 100 to create a percentage change.

To enable more meaningful clinical interpretation, small units were transformed to larger ones. In 6MWT, 1 $\mathrm{m}$ was transformed to $100 \mathrm{~m}$, in hand grip strength $1 \mathrm{~N}$ was transformed to $50 \mathrm{~N}$, in the pain and fatigue scores, 1 $\mathrm{mm}$ was transformed to $10 \mathrm{~mm}$ (VAS).

Spearman's rank correlation between RMDQ at 2 years and each of the independent variables at baseline was performed to evaluate independent variables and reduce the number of independent variables of interest. This analysis was also performed between RMDQ percentages change and each of the independent variables at baseline. Independent variables with $\mathrm{p}<0.20$ were included in next multivariate regression step.

Two forward stepwise multivariate linear regression analyses were performed, one with RMDQ at 2 years as dependent variable and one with RMDQ percentage change as dependent variable. The independent variables remaining from the first step described above were included.

Prior to the multivariate linear regression, the variables were evaluated for the assumptions of multivariate analysis. The dependent variable RMDQ at 2 years fulfilled the assumption of normal distribution when ranked using Blom's formula. ${ }^{49}$ The statistical criteria for the independent variables were 0.05 for entry and 0.10 for removal. Multicollinearity was checked by the values of tolerance and variance inflator factor (VIF). The final models were adjusted for age as it could be a potential confounding factor using standard (Enter) multivariate linear regression. The level of significance for independent variables remaining in the final model was set to 0.05 . The IBM SPSS Windows V.22.0 was used for the statistical analyses.

\section{RESULTS}

Ninety-five per cent $(n=123 / 130)$ of the participants included in the cross-sectional study ${ }^{28}$ could be followed up after 2 years (figure 1). Seven patients could not be assessed at the 2-year follow-up, three of them due to pregnancy, an exclusion criteria in the present study. 


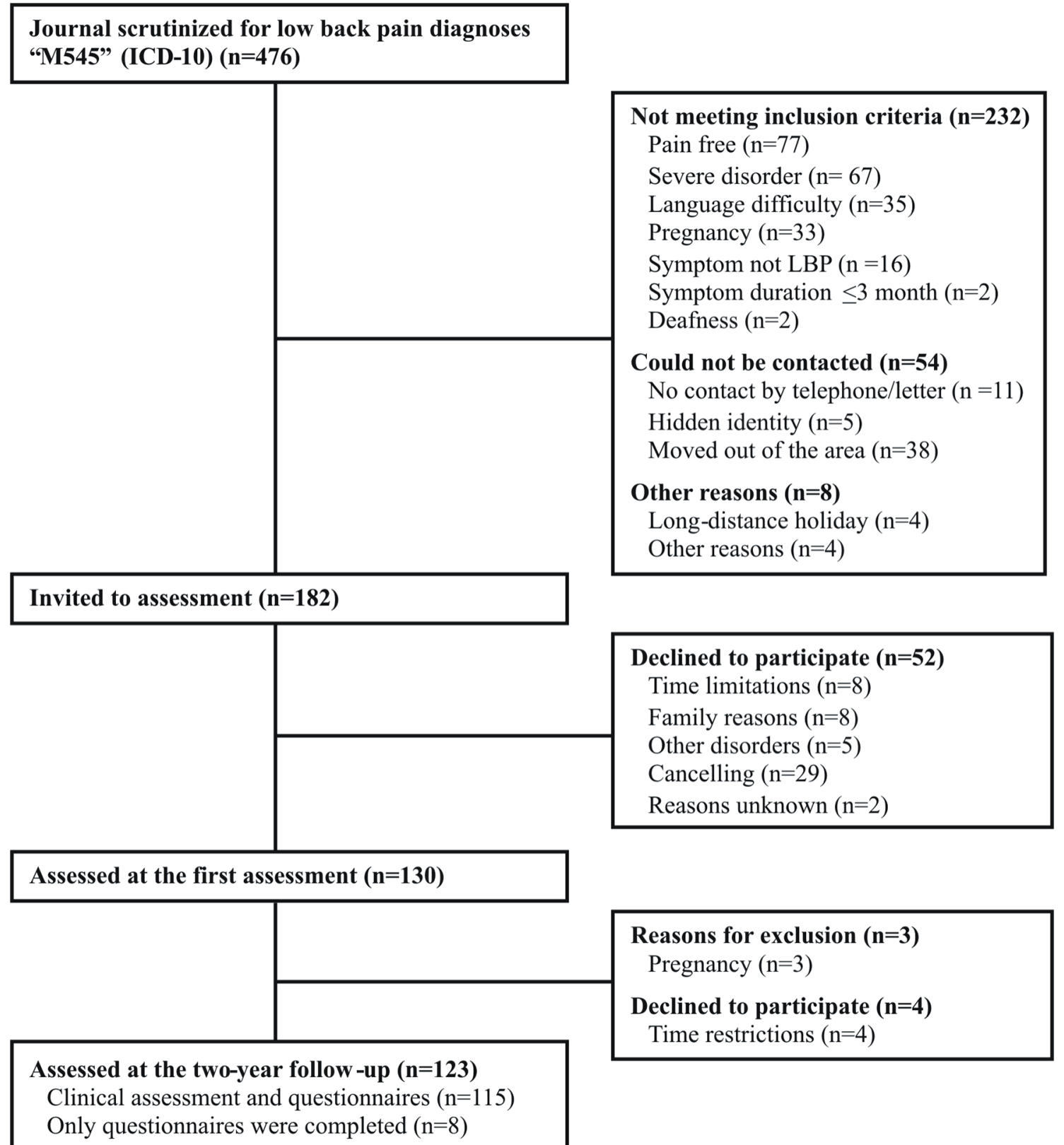

Figure 1 Participants flow. ICD-10, International Classification of Diseases, tenth revision; LBP, low back pain.

The participants were middle-aged (mean 45 (SD $10)$ years $)$, mostly educated $>9$ years $(88 \% ; 108 / 123)$, mainly living with another adult $(76 \% ; 93 / 122)$ and born in Sweden $(90 \%$; 111/123) (table 1). Seventy-nine per cent $(97 / 123)$ were categorised as having work ability at baseline. The BMI mean and median values of 27 (SD 5.5) and 26 (25th; 75th percentile 23; $29)$ indicate that a significant proportion were overweight $(\geq 25 \mathrm{BMI}) .{ }^{50}$ Seventy-six per cent $(n=93 / 123)$ were currently non-smokers and did not exceed risk consumption of alcohol (table 2). Only 14\% (17/123) reported sleeping certainly enough and 19\% (23/121) reported very good sleep quality (table 2 ). Body function, activity, participation and quality of life at baseline indicates that these aspects of life varied and several of them were not optimal (table 2).

\section{Two-year follow-up RMDQ status}

There was a statistically significant mean decrease of 1.9 points (95\% CI 1.2 to 2.5) on RMDQ from 8.4 (SD 4.8) at baseline to 6.4 (SD 5.5) at the 2-year follow-up (-23\%, $\mathrm{p}<0.0001)$.

\section{Predictors for activity limitation (RMDQ) at the 2-year} follow-up

The stepwise multivariate regression analysis showed that the 6MWT, SCI-93 and RMDQ at baseline were the most important predictors explaining $54 \%$ of variance in the RMDQ at the 2-year follow-up (table 3). A model including age, 6MWT and SCI-93 made statistically significant contribution with adjusted $R^{2}$ of 0.39 . However, a model including only RMDQ (with or without addition of age) gave an $\mathrm{R}^{2}$ of 0.51 . Models with 
Table 1 Group characteristics at baseline $(n=123)$

\section{Personal data}

\begin{tabular}{lc} 
Age, years (mean (SD)) & $45(10)$ \\
\hline Nationality Swedish (\% (n/n)) & $90 \%(111 / 123)$ \\
\hline Symptom duration, years (mean (SD)) & $9.6(8.8)$ \\
\hline Education status (\% (n/n)) & \\
$\quad \leq 9$ years & $12 \%(15 / 123)$ \\
\hline 10-12 years & $40 \%(49 / 123)$ \\
\hline 12 years & $48 \%(59 / 123)$ \\
\hline Social status (\% (n/n)) & \\
\hline Living with an adult & $26 \%(32 / 122)$ \\
\hline Living with an adult and child/children & $50 \%(61 / 122)$ \\
\hline Living alone & $12 \%(14 / 122)$ \\
\hline Living alone with child/children & $9.0 \%(11 / 122)$ \\
\hline
\end{tabular}

\section{Pharmacological treatment, yes (\%}

$(\mathrm{n} / \mathrm{n}))^{\star}$

\begin{tabular}{lc} 
Analgesics & $53 \%(65 / 123)$ \\
\hline Psychotropic drugs & $16 \%(20 / 123)$ \\
\hline Employment status (\% (n/n)) & \\
Currently working and/or studying & $58 \%(71 / 123)$ \\
Sick leave, full time & $11 \%(13 / 123)$ \\
\hline Sick leave, part time & $8.9 \%(11 / 123)$ \\
Disability pension, full time & $11 \%(13 / 123)$ \\
Disability pension, part time & $5.7 \%(7 / 123)$ \\
Parental leave, full time & $1.6 \%(2 / 123)$ \\
Parental leave, part time & $1.6 \%(2 / 123)$ \\
Unemployed, full time & $0.81 \%(1 / 123)$ \\
Unemployed, part time & $2.4 \%(3 / 123)$ \\
\hline
\end{tabular}

*The use last month registered by yes or no.

$6 \mathrm{MTW}$ or SCI-93 alone gave $\mathrm{R}^{2}$ of 0.20 and 0.25 , respectively.

There were no significant associations between percentage change in RMDQ and any of the independent variables (table 4 ).

\section{DISCUSSION}

This 2-year prospective cohort study of women with CLBP attending PHC showed that lower performance in walking capacity (6MWT), more severe clinical stress symptoms (SCI-93) and more severe activity limitation (RMDQ) at baseline predicted more activity limitation (RMDQ) after 2years (table 3). The model with these three predictors explained $54 \%$ of the variance in self-reported activity limitation (RMDQ) at the 2-year follow-up, which is similar to a previous review of prediction models including various predictors for disability in patients with subacute non-specific LBP. ${ }^{22}$

\section{Strengths and limitations}

This study included measurements representing all the domains of $\mathrm{ICF}^{17}$ complemented with lifestyle behavioural factors, which is considered as a main strength. The follow-up frequency was very high with $95 \%$ being followed up.

Prevalence and predictors of chronic pain have been studied in general populations, ${ }^{21} 4051$ while the present study assessed women with CLBP consulting PHC, contributing with knowledge for healthcare professionals working in PHC. Previous studies found that chronic pain is more common in women, and that women are at greater risk of chronic pain and disability. ${ }^{640}{ }^{51}$ It has been suggested that women should be assessed separately when studying prognostic factors for LBP, ${ }^{190}$ hence the present study included only female patients.

The initial decision to collect variables was based on previous studies indicating suitable variables of potential interest. However, this decision led to a large number of variables and a further sorting mechanism was needed before the final multivariate regression model. This sorting mechanism could be done either by further using clinical reasoning and prior knowledge or by looking at statistical significance. Each of these approaches will have a different risk for bias. Using clinical reasoning and prior knowledge may make us blind to new knowledge that previous studies missed. Using the approach we finally chose, bivariate correlation in Spearman's rank correlation may cause clinically insignificant findings to be put forward.

Hence, each independent variable was first evaluated in this bivariate analysis. Second, the multivariate model was built by using the independent variables with $p<0.20$ in the rank correlation. Physical performance (6MWT) was included in the final model. Knowing that age influences physical performance, age was included as a potential confounder, even though it was not correlated with RMDQ.

The main reason for deploying a sorting mechanism (Spearman's rank correlation) before doing the multivariate regression was to reduce the problem which may occur when there are few participants relative to the number of independent variables. Hence, the number of participants was considered to be sufficient for the final model.

Prior to the multiple regression, the independent variables were also evaluated for assumptions of multivariate analysis including checking for multicollinearity and singularity. The values of tolerance $(0.52-0.74)$ and VIF (1.3-1.9) were checked indicating low correlation between the independent variables. Moreover, questionnaires total scores were used to avoid singularity.

Self-administrated questionnaires are recommended for the assessment of activity limitation in patients with LBP. $^{52}$ The present study used RMDQ as the outcome measure at the 2-year follow-up. The RMDQ is considered valid, commonly used and recommended in LBP research for monitoring disability. ${ }^{53}$ Seventeen 
Table 2 Lifestyle factors, body function, activity, participation and health-related quality of life at baseline $(n=123)$

\section{Lifestyle behavioural factors}

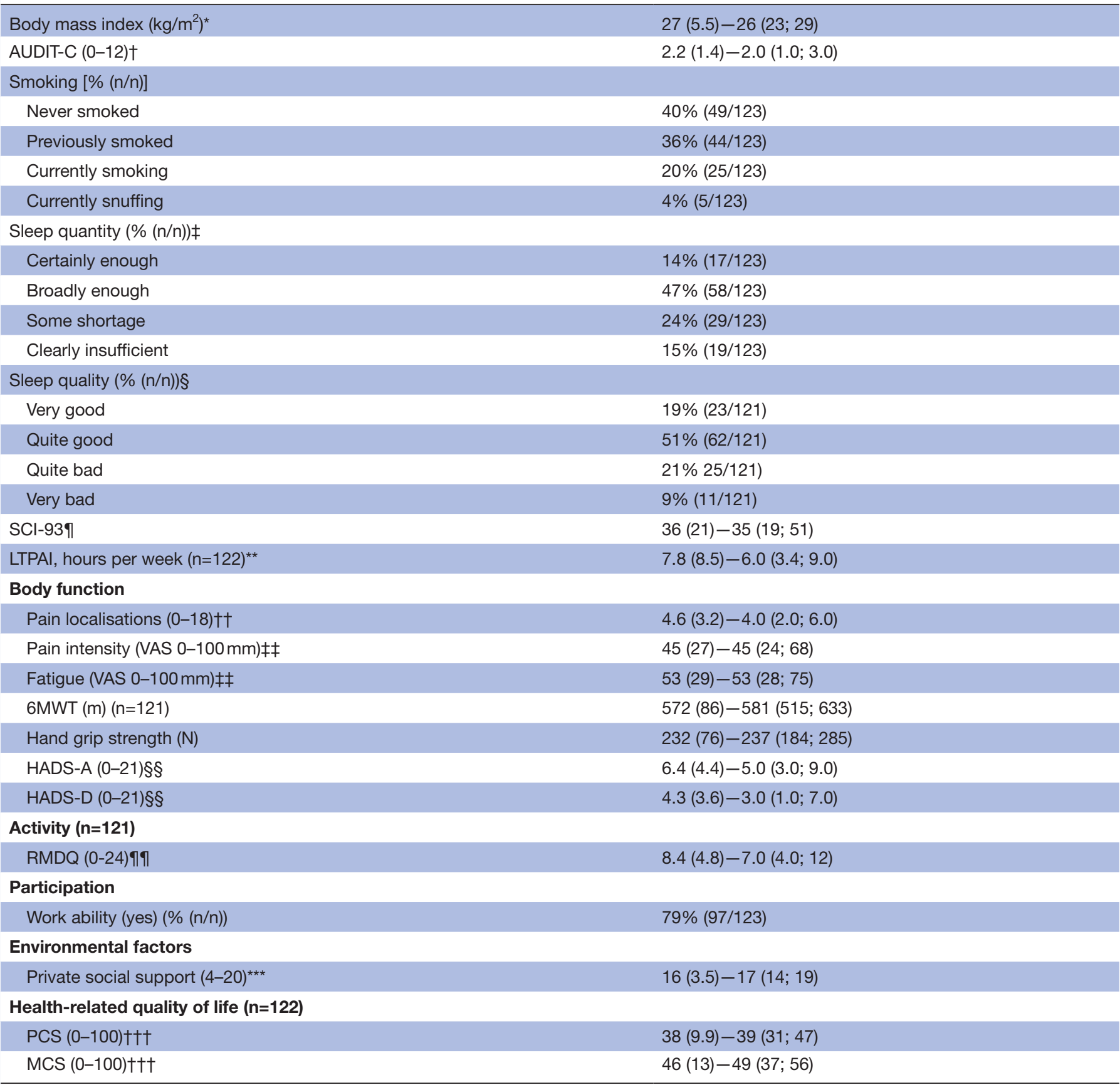

${ }^{*}$ First figure mean values (SD). Second figure median values (25th; 75 th percentile).

†The AUDIT-C, three items. Higher scores reflect higher alcohol consumption (0-12).

‡One item: 'Do you think you get enough sleep?'

$\S$ One item: 'On the whole, how do you think you sleep?'

IHigher scores indicate more severe clinical stress symptoms (0-140).

${ }^{* *}$ LTPAl assesses the total hours of physical activity in leisure time during a typical week.

††Self-reported pain locations registered by a figure with predefined body locations (0-18).

$\ddagger \ddagger$ Perceived pain intensity, fatigue over the last week rated on a VAS $(0-100)$. Higher values indicate more pain, fatigue.

$\S \S$ Higher scores indicate more anxiety (0-21) and depression (0-21).

१ๆRMDQ indicates disability related to low back pain (0-24) at baseline. Higher scores indicate more severe disability.

${ }^{* * *}$ Medical Outcome Study Social Support Survey (four-item scale) reflects private social support ranging from 1 to 5 . Higher scores reflect more perceived support (4-20).

†††SF-36. The PCS score (0-100) and MCS score (0-100).

6MWT, 6 min walk test; AUDIT-C, Alcohol Use Disorders Identification Test; HADS-A and HADS-D, Hospital Anxiety and Depression Scale; LTPAl, leisure time physical activity instrument; MCS, mental component summary; PCS, physical component summary; RMDQ, Roland Morris disability questionnaire; SCI-93, Stress and Crisis Inventory; SF-36, short-form health survey; VAS, visual analogue scale. 
Table 3 Prognostic factors at baseline for activity limitation at the later 2-year follow-up using the Roland Morris disability questionnaire (RMDQ) at 2-year follow-up ( $n=120)$

\begin{tabular}{|c|c|c|c|c|c|}
\hline & \multicolumn{3}{|c|}{$\begin{array}{l}\text { Spearman's rank correlation } \\
\text { Correlation with RMDQ at } 2 \text { years }\end{array}$} & \multicolumn{2}{|c|}{$\begin{array}{l}\text { Forward stepwise multivariate linear } \\
\text { regression* } \\
\text { Independent variables } p<0.20 \text { entered in the } \\
\text { model, adjusted for age } \\
\mathbf{R}^{2}=0.54 \text { for the overall model }\end{array}$} \\
\hline & $\mathbf{N}$ & $r$ & p Value & $\beta(95 \% \mathrm{Cl})$ & p Value \\
\hline Age, years & 120 & 0.067 & 0.47 & $-0.0048(-0.019$ to 0.010$)$ & 0.51 \\
\hline \multicolumn{6}{|l|}{ Lifestyle behavioural factors } \\
\hline Body mass index $\left(\mathrm{kg} / \mathrm{m}^{2}\right)$ & 119 & 0.21 & 0.021 & & \\
\hline Smoker $(n=72)-$ non-smoker $(n=48)$ & 120 & 0.14 & 0.14 & & \\
\hline AUDIT-C (0-12)† & 118 & -0.23 & 0.011 & & \\
\hline Sleep quantity (1-4)‡ & 120 & -0.34 & 0.00014 & & \\
\hline Sleep quality (1-4)§ & 118 & -0.43 & $<0.0001$ & & \\
\hline SCl-93ף & 120 & 0.48 & $<0.0001$ & 0.0091 (0.0023 to 0.016$)$ & 0.0088 \\
\hline LTPAI (hours per week) ${ }^{\star \star}$ & 119 & -0.11 & 0.24 & & \\
\hline \multicolumn{6}{|l|}{ Body function } \\
\hline Pain localisations $(0-18)+\dagger$ & 120 & 0.36 & 0.000052 & & \\
\hline 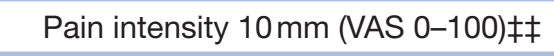 & 120 & 0.20 & 0.027 & & \\
\hline 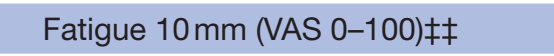 & 120 & 0.24 & 0.0078 & & \\
\hline 6MWT, $100 \mathrm{~m}$ & 118 & -0.41 & $<0.0001$ & $-0.23(-0.42$ to -0.036$)$ & 0.020 \\
\hline Hand grip strength $50(\mathrm{~N})$ & 120 & -0.17 & 0.070 & & \\
\hline HADS-A (0-21) §§ & 120 & 0.16 & 0.089 & & \\
\hline HADS-D (0-21)§§ & 120 & 0.37 & 0.000025 & & \\
\hline \multicolumn{6}{|l|}{ Activity } \\
\hline RMDQ at baseline (0-24)ๆๆ & 118 & 0.71 & $<0.0001$ & 0.10 (0.068 to 0.14$)$ & $<0.0001$ \\
\hline \multicolumn{6}{|l|}{ Participation } \\
\hline $\begin{array}{l}\text { Work ability }(n=95)-\text { no work ability } \\
(n=25)\end{array}$ & 120 & -0.37 & 0.000026 & & \\
\hline \multicolumn{6}{|l|}{ Environmental factors } \\
\hline Private social support $(4-20)^{\star \star \star}$ & 120 & -0.29 & 0.0013 & & \\
\hline \multicolumn{6}{|l|}{ Health-related quality of life } \\
\hline PCS $(0-100)+\dagger \dagger$ & 119 & -0.42 & $<0.0001$ & & \\
\hline MCS (0-100)††† & 119 & -0.28 & 0.0022 & & \\
\hline
\end{tabular}

*RMDQ score was transformed to ranked normal score of RMDQ using Blom's formula. The final model was adjusted for age using standard (Enter) multivariate linear regression.

†The AUDIT-C, three items. Higher scores reflect higher alcohol consumption (0-12).

ҒOne item: ‘Do you think you get enough sleep?'. Higher scores indicate better sleep (1-4).

$\S$ One item: 'On the whole, how do you think you sleep?'. Higher scores indicate better sleep (1-4).

१Higher scores indicate more severe clinical stress symptoms (0-140).

**The LTPAI assesses the total hours of physical activity in leisure time during a typical week.

$\dagger †$ Self-reported pain locations registered by a figure with predefined body locations (0-18).

$\ddagger \ddagger$ Perceived pain intensity, fatigue over the last week rated on a VAS (0-100). Higher values indicate more pain, fatigue.

$\S \S$ Higher scores indicate more anxiety (0-21) and depression (0-21).

११RMDQ indicates disability related to low back pain (0-24) at baseline. Higher scores indicate more severe disability.

${ }^{* \star \star}$ Medical Outcome Study Social Support Survey (four-item scale) reflects private social support ranging from 1 to 5 . Higher scores reflect more perceived support (4-20).

†††SF-36. The PCS score (0-100) and MCS score (0-100).

6MWT, 6 min walk test; AUDIT-C, Alcohol Use Disorders Identification Test; HADS-A and HADS-D, Hospital Anxiety and Depression Scale;

LTPAI, leisure time physical activity instrument; MCS, mental component summary; PCS, physical component summary; SCI-93, Stress and

Crisis Inventory; SF-36, short-form health survey; VAS, visual analogue scale. 
Table 4 Prognostic factors at baseline for percentage change in the Roland Morris disability questionnaire (RMDQ) ( $=115)$

Forward stepwise multivariate linear regression*

Spearman's rank correlation Independent variables $p<0.20$ entered in the Correlation with percentage model, adjusted for age change in RMDQ No significant association

\begin{tabular}{|c|c|c|c|c|c|}
\hline & $\mathbf{N}$ & $r$ & $\mathrm{p}$ Value & $\beta(95 \% \mathrm{Cl})$ & p Value \\
\hline Age, years & 115 & -0.11 & 0.23 & $-0.0017(-0.014$ to 0.011$)$ & 0.79 \\
\hline \multicolumn{6}{|l|}{ Lifestyle behavioural factors } \\
\hline Body mass index $\left(\mathrm{kg} / \mathrm{m}^{2}\right)$ & 114 & -0.13 & 0.18 & & \\
\hline Smoker $(n=72)-$ non-smoker $(n=48)$ & 115 & -0.072 & 0.44 & & \\
\hline AUDIT-C (0-12)† & 113 & 0.11 & 0.23 & & \\
\hline Sleep quantity $(1-4) \ddagger$ & 115 & 0.18 & 0.054 & & \\
\hline Sleep quality $(1-4) \S$ & 113 & 0.16 & 0.099 & & \\
\hline SCl-939 & 115 & -0.17 & 0.075 & & \\
\hline LTPAI (hours per week) ${ }^{\star *}$ & 115 & 0.13 & 0.18 & & \\
\hline \multicolumn{6}{|l|}{ Body function } \\
\hline Pain localisations $(0-18) \dagger \dagger$ & 115 & -0.15 & 0.10 & & \\
\hline Pain intensity $10 \mathrm{~mm}$ (VAS 0-100)‡‡ & 115 & 0.078 & 0.41 & & \\
\hline 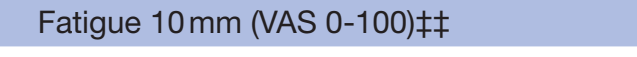 & 115 & -0.046 & 0.62 & & \\
\hline 6MWT, 100 m & 113 & 0.17 & 0.065 & & \\
\hline Hand grip strength $50(\mathrm{~N})$ & 115 & 0.057 & 0.55 & & \\
\hline HADS-A (0-21) §§ & 115 & -0.023 & 0.81 & & \\
\hline HADS-D (0-21)§§ & 115 & -0.11 & 0.24 & & \\
\hline \multicolumn{6}{|l|}{ Participation } \\
\hline Work ability $(n=95)-$ no work ability $(n=25)$ & 115 & 0.15 & 0.11 & & \\
\hline \multicolumn{6}{|c|}{ Environmental factors } \\
\hline Private social support (4-20)ףๆ & 115 & 0.14 & 0.14 & & \\
\hline \multicolumn{6}{|l|}{ Health-related quality of life } \\
\hline PCS $(0-100)^{\star \star \star}$ & 114 & 0.029 & 0.76 & & \\
\hline $\operatorname{MCS}(0-100)^{\star \star \star}$ & 114 & 0.14 & 0.13 & & \\
\hline
\end{tabular}

*Percentage change in RMDQ as dependent variable. The final model was adjusted for age using standard (Enter) multivariate linear regression.

†The AUDIT-C, three items. Higher scores reflect higher alcohol consumption (0-12).

‡One item: 'Do you think you get enough sleep?'. Higher scores indicate better sleep (1-4).

§One item: 'On the whole, how do you think you sleep?'. Higher scores indicate better sleep (1-4).

ПHigher scores indicate more severe clinical stress symptoms (0-140).

${ }^{\star *}$ The LTPAl assesses the total hours of physical activity in leisure time during a typical week.

$\dagger †$ Self-reported pain locations registered by a figure with predefined body locations (0-18).

ł‡Perceived pain intensity, fatigue over the last week rated on a VAS (0-100). Higher values indicate more pain, fatigue.

$\S \S$ Higher scores indicate more anxiety (0-21) and depression (0-21).

१ๆMedical Outcome Study Social Support Survey (four-item scale) reflects private social support ranging from 1 to 5 . Higher scores reflect more perceived support (4-20).

${ }^{* * *}$ SF-36. The PCS score $(0-100)$ and MCS score $(0-100)$.

6MWT, 6 min walk test; AUDIT-C, Alcohol Use Disorders Identification Test; HADS-A and HADS-D, Hospital Anxiety and Depression Scale; LTPAI, leisure time physical activity instrument; MCS, mental component summary; PCS, physical component summary; SCI-93, Stress and Crisis Inventory; SF-36, short-form health survey; VAS, visual analogue scale.

statements in the RMDQ are reported to be linked to the activity component in the ICF. ${ }^{55}{ }^{56}$ However, self-reports may suffer from the fact that some patients may underestimate or overestimate their limitations and physical performance tests are suggested to complement self-reports. ${ }^{57}$ Walk capacity $(6 \mathrm{MWT})$ and hand grip strength, semiobjective measures of body function, were therefore included as potential predictors in this study.

The group showed a moderate grade of disability, RMDQ 8.4 (SD 4.8), at baseline which might reflect that the women included were not in acute need for treatment 
when recruited. There was a statistically significant mean decrease of approximately two points on RMDQ during the 2-year period. Minimal clinical detectable change in the RMDQ is considered to be $2-3$ points. Others have suggested a change of $4-5$ points to be of clinical value. ${ }^{53}$

\section{Predictors for activity limitation (RMDQ) at 2-year follow-up}

The BMI values corresponded with overweight (mean 27 (SD 5.5)), which is common in patients with chronic pain $^{28} 58$ and might be due to impaired body function, activity limitation and restrictions of participation. A previous 1-year follow-up study found self-reported weight and height (BMI) as a significant predictor for activity limitation. ${ }^{59}$ However, this could not be confirmed in the present study.

Previously or currently smoking was not found as a predictor, which is concordant to a review studying prognostic factors for pain and disability in CLBP. ${ }^{26}$ In the present study, hours per week of LTPAI (mean 7.8 (SD $8.5)$ ) was within recommended levels of physical activity ${ }^{60}$ which might have been the reason for no prognostic value. A healthy lifestyle behaviour, combinations of lifestyles factors, is reported to influence the prognosis of LBP. ${ }^{21}$ It could be interesting to combine and categorise various self-reported lifestyle behavioural factors for analysing their prognostic value for patients with CLBP. However, in the present study the prognostic values of lifestyle behavioural factors were analysed separately for later self-reported activity limitation in CLBP.

Previous prospective studies of LBP have evaluated body function by measuring spinal motion and muscle strength, showing them to be of poor prognostic value. ${ }^{1161}$ In the present study, the body function assessed by the $6 \mathrm{MWT}$ was of prognostic value, showing that lower performance in the $6 \mathrm{MWT}$ at baseline predicted more severe activity limitation at 2-year follow-up. Therefore, the 6MWT could be included as a complement to standard clinical examination of CLBP. Physical activity is a recommended intervention for patients with CLBP. The 6MWT is easy to perform and provides information of an individual's physical performance. In the future, the 6MWT might be used as a self-administrated assessment tool to promote physical activity and self-management strategies for patients with CLBP. However, the utility of 6MWT as a self-assessment tool needs to be studied further.

More severe clinical stress symptoms (SCI-93) could independently predict more severe activity limitation (RMDQ) at the 2-year follow-up (table 3). The mean score for SCI-93 at baseline was 36 (SD 21) (table 2), which indicates an increased level of clinical stress symptoms in the group, compared with the reference values. ${ }^{32}{ }^{33}$ Signs and symptoms in patients with chronic pain are suggested to be associated with prolonged stress ${ }^{62}$ but measurement of clinical stress symptoms is not standard in the clinical assessment of patients with CLBP. Therefore, the SCI-93 could provide valuable information for predicting later activity limitation for these patients. Moreover, questionnaires assessing symptoms severity might stimulate the patient's motivation in using active coping strategies to alleviate their stress responses. ${ }^{32}$ Stress reduction interventions have shown to improve pain acceptance. ${ }^{63}$ However, if pain acceptance might mediate the association of stress, physical activity and disability need further investigation.

Studies of prognostic factors for patients with acute LBP report similar predictors as this study to the ones in this study ${ }^{6465}$ However, the characteristics of the patients in the study used to derive the predictive model have to be similar to those in whom the model will be used to. Various factors can impact disability in patients with CLBP ( $>12$ weeks duration) and function and functional demands often differ between women and men. Therefore, women with CLBP were included in this study.

The baseline activity limitation (RMDQ) was the strongest predictor $\left(\mathrm{R}^{2} 0.51\right)$ for activity limitation (RMDQ) at 2 years. The prognostic model including the baseline RMDQ, 6MWT and SCI-93 explained 54\% of the variance in activity limitation (RMDQ) at the 2-year follow-up (table 3), which is slightly more compared with findings in a previous review of different prognostic models explaining $28 \%-51 \%$ of variance in persisting disability in subacute LBP. ${ }^{22}$ The 6MWT and SCI-93 may add useful information where the outcome of RMDQ is unavailable.

Knowledge about factors that are associated with the probable recovery or not in CLBP can be used to improve the management of patients with CLBP in primary care. The results of this study can give guidance for interventional trials aiming to improve physical capacity and decrease stress in women with CLBP. The impact of the interaction between prognostic factors and interventions on activity limitation in women with CLBP needs further investigation.

\section{CONCLUSION}

A walk test (6MWT), clinical stress symptoms (SCI-93) and activity limitation (RMDQ) predicted future activity limitation in women with CLBP within PHC. The prognostic model including these three predictors explained $54 \%$ of the variance in self-reported activity limitation (RMDQ) after 2 years.

\section{Author affiliations \\ ${ }^{1}$ Research and Development Center Södra Älvsborg, Närhälsan, Research and Development Primary Health Care Region Västra Götaland, Borås, Sweden ${ }^{2}$ Department of Health and Rehabilitation, Unit of Physiotherapy, Sahlgrenska Academy, Institute of Neuroscience and Physiology, University of Gothenburg, Göteborg, Sweden \\ ${ }^{3}$ Närhälsan, Health Unit, Primary Health Care Region, Västra Götaland, Sweden ${ }^{4}$ Department of Public Health and Community Medicine, University of Gothenburg, Sahlgrenska Academy, Institute of Medicine, Gothenburg, Sweden \\ ${ }^{5}$ Cairns clinical school, College of Medicine and Dentistry, James Cook University, Australia}

Contributors LN contributed to the design of the study, was responsible for the data collection, participated in the statistical analysis, interpreted the data and drafted the first manuscript. LT contributed to the interpretation of data and revision of manuscript for important content. RG and KM contributed to the design of the study, participated in the statistical analysis, interpreted the data and critically 
revised all versions of the manuscript. All authors read and approved the final manuscript.

Funding Financial support was obtained from the research and development council of Södra Älvsborg, Region Västra Götaland, Sweden. The Health \& Medical Care Committee of the Regional Executive Board, Region Västra Götaland, Sweden.

Competing interests None declared.

Ethics approval Regional Ethical Review Board in Gothenburg, Sweden.

Provenance and peer review Not commissioned; externally peer reviewed.

Data sharing statement No additional data are available.

Open Access This is an Open Access article distributed in accordance with the Creative Commons Attribution Non Commercial (CC BY-NC 4.0) license, which permits others to distribute, remix, adapt, build upon this work non-commercially, and license their derivative works on different terms, provided the original work is properly cited and the use is non-commercial. See: http://creativecommons.org/ licenses/by-nc/4.0/

(C) Article author(s) (or their employer(s) unless otherwise stated in the text of the article) 2017. All rights reserved. No commercial use is permitted unless otherwise expressly granted.

\section{REFERENCES}

1. SBU. Ont i ryggen ont i nacken. en evidensbaserad kunskapssammanställning. SBU rapport 145, $1 \& 2$ (Back pain, neck pain; An evidence based review. Report no. 145, 1\&2). Stockholm: The Swedish Council on Technology Assessment in Health Care, 2000. Summary and conclusions available in English at the same web site. http://www.sbu.se. (accessed 11 Jul 2010).

2. Waddell G. Back Pain Revolution. Second edition ed. Edinburgh: Churchill Livingstone, 2004.

3. Airaksinen O, Brox JI, Cedraschi C, et al. Chapter 4. european guidelines for the management of chronic nonspecific low back pain Eur Spine J 2006;15(Suppl 2):s192-s300.

4. Björck-van Dijken C, Fjellman-Wiklund A, Hildingsson C. Low back pain, lifestyle factors and physical activity: a population based-study. $J$ Rehabil Med 2008;40:864-9.

5. Koes BW, van Tulder MW, Ostelo R, et al. Clinical guidelines for the management of low back pain in primary care: an international comparison. Spine 2001;26:2504-13.

6. Thomas E, Silman AJ, Croft PR, et al. Predicting who develops chronic low back pain in primary care: a prospective study. BMJ 1999;318:1662-7.

7. Von Korff M, Deyo RA, Cherkin D, et al. Back pain in primary care. outcomes at 1 year. Spine 1993;18:855-62.

8. Von Korff M, Saunders K. The course of back pain in primary care. Spine 1996;21:2833-7.

9. Henschke N, Maher CG, Refshauge KM, et al. Prognosis in patients with recent onset low back pain in Australian primary care: inception cohort study. BMJ 2008;337:a171.

10. Enthoven P, Skargren E, Oberg B. Clinical course in patients seeking primary care for back or neck pain: a prospective 5-year follow-up of outcome and health care consumption with subgroup analysis. Spine 2004;29:2458-65.

11. Enthoven P, Skargren E, Carstensen J, et al. Predictive factors for 1-year and 5-year outcome for disability in a working population of patients with low back pain treated in primary care. Pain 2006;122:137-44.

12. Grotle M. Clinical course and prognostic factors in patients with low back pain and disability: a methodological and clinical study. University of Oslo, 2004.

13. Pincus T, Burton AK, Vogel S, et al. A systematic review of psychological factors as predictors of chronicity/disability in prospective cohorts of low back pain. Spine 2002;27:E109-20.

14. Pincus T, Vlaeyen JW, Kendall NA, et al. Cognitive-behavioral therapy and psychosocial factors in low back pain: directions for the future. Spine 2002;27:E133-8.

15. Pengel LH, Herbert RD, Maher CG, et al. Acute low back pain: systematic review of its prognosis. BMJ 2003;327:323.

16. Schiøttz-Christensen B, Nielsen GL, Hansen VK, et al. Long-term prognosis of acute low back pain in patients seen in general practice: a 1-year prospective follow-up study. Fam Pract 1999;16:223-32.

17. WHO. International classification function disability and health. 2001. http://www.who.int/classifications/icf/en/ (cited 201319 Dec).
18. Hayden JA, Chou R, Hogg-Johnson S, et al. Systematic reviews of low back pain prognosis had variable methods and results: guidance for future prognosis reviews. J Clin Epidemiol 2009;62:781-96.

19. Messing K, Stock SR, Tissot F. Should studies of risk factors for musculoskeletal disorders be stratified by gender? lessons from the 1998 Québec Health and Social Survey. Scand J Work Environ Health 2009;35:96-112.

20. Chenot JF, Becker A, Leonhardt C, et al. Sex differences in presentation, course, and management of low back pain in primary care. Clin J Pain 2008;24:578-84.

21. Bohman T, Alfredsson L, Jensen I, et al. Does a healthy lifestyle behaviour influence the prognosis of low back pain among men and women in a general population? A population-based cohort study. BMJ Open 2014;4:e005713.

22. Hilfiker R, Bachmann LM, Heitz CA, et al. Value of predictive instruments to determine persisting restriction of function in patients with subacute non-specific low back pain. systematic review. Eur Spine J 2007;16:1755-75.

23. Grotle M, Foster NE, Dunn KM, et al. Are prognostic indicators for poor outcome different for acute and chronic low back pain consulters in primary care? Pain 2010;151:790-7.

24. Costa LC, Maher CG, McAuley JH, et al. Prognosis for patients with chronic low back pain: inception cohort study. BMJ 2009;339:b3829.

25. Hayden JA, Dunn KM, van der Windt DA, et al. What is the prognosis of back pain? Best Pract Res Clin Rheumatol 2010;24:167-79.

26. Verkerk K, Luijsterburg PA, Miedema HS, et al. Prognostic factors for recovery in chronic nonspecific low back pain: a systematic review. Phys Ther 2012;92:1093-108.

27. Nordeman L, Gunnarsson R, Mannerkorpi K. Prognostic factors for work ability in women with chronic low back pain consulting primary health care: a 2-year prospective longitudinal cohort study. Clin J Pain 2014;30:391-8.

28. Nordeman L, Gunnarsson R, Mannerkorpi K. Prevalence and characteristics of widespread pain in female primary health care patients with chronic low back pain. Clin J Pain 2012;28:65-72.

29. Bush K, Kivlahan DR, McDonell MB, et al. The AUDIT alcohol consumption questions (AUDIT-C): an effective brief screening test for problem drinking. Ambulatory Care Quality Improvement Project (ACQUIP). Alcohol Use Disorders identification test. Arch Intern Med 1998;158:1789-95.

30. Akerstedt T, Knutsson A, Westerholm P, et al. Sleep disturbances, work stress and work hours: a cross-sectional study. J Psychosom Res 2002;53:741-8.

31. Nyström C, Nyström O. Skattad stress verifierar fysiska stressymtom] Estimated stress verifies autonomic dysfunction. Läkartidningen 1996;93:2583-4.

32. Ericsson A, Nyström C, Mannerkorpi K. Psychometric properties of the stress and crisis Inventory (SCl-93) in females with fibromyalgia and chronic widespread pain. Nord J Psychiatry 2015;69:28-34.

33. Kraft BNC, Nyström O, Pedersen C. Stressreaktion och välfärdsdata - en populationsstudie (in Swedish) [Stress reactions and welfare data - A population study]. Socialmedicinsk Tidskrift 2004;3:222-9.

34. Mannerkorpi K, Hernelid C. Leisure time physical activity instrument and physical activity at Home and Work Instrument. Development, face validity, construct validity and test-retest reliability for subjects with Fibromyalgia. Disabil Rehabil 2005;27:695-701.

35. Pankoff BA, Overend TJ, Lucy SD, et al. Reliability of the sixminute walk test in people with Fibromyalgia. Arthritis Care Res 2000;13:291-5

36. King S, Wessel J, Bhambhani Y, et al. Validity and reliability of the 6 minute walk in persons with Fibromyalgia. J Rheumatol 1999;26:2233-7.

37. Harding VR, Williams AC, Richardson $\mathrm{PH}$, et al. The development of a battery of measures for assessing physical functioning of chronic pain patients. Pain 1994;58:367-75.

38. Mannerkorpi K, Svantesson U, Broberg C. Relationships between performance-based tests and patients' ratings of activity limitations, self-efficacy, and pain in Fibromyalgia. Arch Phys Med Rehabil 2006;87:259-64.

39. Nordenskiöld UM, Grimby G. Grip force in patients with rheumatoid arthritis and Fibromyalgia and in healthy subjects. A study with the Grippit instrument. Scand J Rheumatol 1993;22:14-19.

40. Bergman S, Herrström P, Högström K, et al. Chronic musculoskeleta pain, prevalence rates, and sociodemographic associations in a swedish population study. J Rheumato/ 2001;28:1369-77.

41. Lisspers J, Nygren A, Söderman E. Hospital anxiety and depression Scale (HAD): some psychometric data for a Swedish sample. Acta Psychiatr Scand 1997;96:281-6.

42. Zigmond AS, Snaith RP. The hospital anxiety and depression scale. Acta Psychiatr Scand 1983;67:361-70. 
43. Johansson E, Lindberg P. Subacute and chronic low back pain. reliability and validity of a swedish version of the Roland and Morris Disability Questionnaire. Scand J Rehabil Med 1998;30:139-43

44. Linton SJ, Halldén K, Hellsing A-L. The reliability of self-reported sick absenteeism a pilot study. 1995;24:145-50.

45. Gjesfjeld CD, Greeno CG, Kim KH. A confirmatory factor analysis of an abbreviated Social support instrument: the MOS-SSS. Res Soc Work Pract 2008;18:231-7.

46. Sullivan M, Karlsson J. The Swedish SF-36 Health Survey III. evaluation of criterion-based validity: results from normative population. J Clin Epidemiol 1998;51:1105-13.

47. Sullivan M, Karlsson J, Ware JE. The Swedish SF-36 Health Survey-I. evaluation of data quality, scaling assumptions, reliability and construct validity across general populations in Sweden. Soc Sci Med 1995;41:1349-58.

48. Persson LO, Karlsson J, Bengtsson C, et al. The Swedish SF-36 Health Survey II. evaluation of clinical validity: results from population studies of elderly and women in Gothenborg. $J$ Clin Epidemiol 1998;51:1095-103.

49. Blom G. Statistical estimates and transformed beta variables. New York: John Wiley and Sons, 1958.

50. WHO. BMI classification. http://apps.who.int/bmi/index.jsp? introPage=intro_3.html (accessed 15 Jul 2015).

51. Andersson HI, Ejlertsson G, Leden I, et al. Chronic pain in a geographically defined general population: studies of differences in age, gender, social class, and pain localization. Clin J Pain 1993;9:174-82.

52. Pincus T, Santos R, Breen A, et al. A review and proposal for a core set of factors for prospective cohorts in low back pain: a consensus statement. Arthritis Rheum 2008:59:14-24.

53. Deyo RA, Battie M, Beurskens AJ, et al. Outcome measures for low back pain research. A proposal for standardized use. Spine 1998;23:2003-13.

54. Smeets R, Köke A, Lin CW, et al. Measures of function in low back pain/disorders: low back Pain Rating Scale (LBPRS), Oswestry Disability Index (ODI), Progressive Isoinertial Lifting evaluation (PILE), Quebec Back Pain Disability Scale (QBPDS), and Roland-Morris
Disability Questionnaire (RDQ). Arthritis Care Res 2011;63(Suppl 11):S158-73.

55. Sigl T, Cieza A, Brockow T, et al. Content comparison of low back pain-specific measures based on the International classification of functioning, disability and Health (ICF). Clin J Pain 2006;22:147-53.

56. Grotle M, Brox JI, Vøllestad NK. Functional status and disability questionnaires: what do they assess? A systematic review of backspecific outcome questionnaires. Spine 2005;30:130-40.

57. Lee CE, Simmonds MJ, Novy DM, et al. Self-reports and clinicianmeasured physical function among patients with low back pain: a comparison. Arch Phys Med Rehabil 2001;82:227-31.

58. Mannerkorpi K, Nordeman L, Ericsson A, et al. Pool exercise for patients with Fibromyalgia or chronic widespread pain: a randomized controlled trial and subgroup analyses. J Rehabil Med 2009;41:751-60.

59. Wilkens P, Scheel IB, Grundnes O, et al. Prognostic factors of prolonged disability in patients with chronic low back pain and lumbar degeneration in primary care: a cohort study. Spine 2013;38:65-74

60. WHO. Global strategy on Diet. Physical Activity and Health: Physical Activity and Adults. http://www.who.int/dietphysicalactivity/ factsheet_adults/en/.

61. Grotle M, Brox JI, Veierød MB, et al. Clinical course and prognostic factors in acute low back pain: patients consulting primary care for the first time. Spine 2005;30:976-82.

62. Ellegaard H, Pedersen BD. Stress is dominant in patients with depression and chronic low back pain. A qualitative study of psychotherapeutic interventions for patients with non-specific low back pain of 3-12 months' duration. BMC Musculoskelet Disord 2012;13:166.

63. Jeong $\mathrm{S}$, Cho S. Acceptance and patient functioning in chronic pain: the mediating role of physical activity. Qual Life Res 2017;26.

64. Hayden JA, Chou R, Hogg-Johnson S, et al. Systematic reviews of low back pain prognosis had variable methods and results: guidance for future prognosis reviews. J Clin Epidemiol 2009;62:781-96.

65. Mallen CD, Peat G, Thomas E, et al. Prognostic factors for musculoskeletal pain in primary care: a systematic review. $\mathrm{Br} J \mathrm{Gen}$ Pract 2007;57:655-61. 